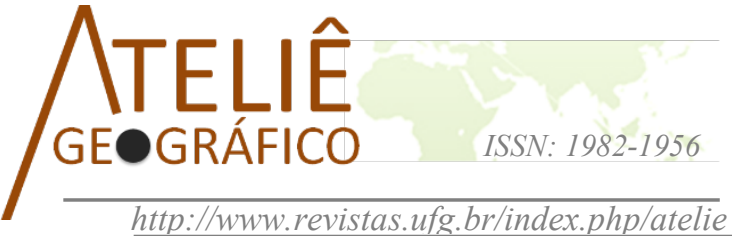

\section{Cartografia Escolar Inclusiva: o jogo digital educacional como instrumento na alfabetização cartográfica de alunos surdos e deficientes auditivos}

\author{
Inclusive School Cartography: the digital educational game \\ as an instrument in cartographic literacy and deaf and \\ hearing impaired students
}

Cartographie Scolaire Inclusive: le jeu éducatif numérique en tant qu'instrument de littératie cartographique pour les élèves sourds et malentendants

Tuane Telles Rodrigues

Universidade Federal de Santa Maria

tuanytel@hotmail.com

Roberto Cassol

Universidade Federal de Santa Maria

rtocassol@gmail.com

Wilson de Oliveira Miranda

Universidade Federal de Santa Maria

wilsonmirandaufsm@gmail.com

\begin{abstract}
Resumo
As novas metodologias no ensino de Geografia têm buscado propostas modernas para a aproximação entre as comunidades que compõem a sociedade, o que se convencionou chamar de educação inclusiva. Nesse sentido, a pesquisa aqui relatada buscou contribuir no aperfeiçoamento das técnicas voltadas ao ensino e à aprendizagem da Cartografia Escolar de alunos surdos e deficientes auditivos, no município de Santa Maria, RS. A metodologia empregada foi estruturada em três fases: a primeira, na observação dos alunos da Escola Estadual de Educação Especial Dr. Reinaldo Fernando Cóser; a segunda, foi a construção do perfil dos alunos surdos e deficientes auditivos que estudam no município; a terceira, a avaliação das impressões dos alunos em relação ao jogo digital "CartoCon: Nossa Expedição geográfica", através da abordagem qualitativa. Os resultados obtidos foram positivos, evidenciando que o jogo digital, quando adaptado às condições dos alunos, é um
\end{abstract}


recurso viável no ensino inclusivo de Cartografia Escolar, atendendo demandas dos estudantes que integram a comunidade surda do município.

Palavras-chave: Ensino de Geografia. Cartografia Escolar Inclusiva. Jogo digital.

\begin{abstract}
The new methodologies in the teaching of geography have been seeking modern proposals for the approximation between the communities that make up the society, what is conventionally called inclusive education. In this sense, the research reported here sought to contribute to the improvement of techniques aimed at teaching and learning the School Cartography of deaf and deaf students in the municipality of Santa Maria, RS. The methodology employed was structured in three phases: the first, in the observation of the students of the Dr. Reinaldo Fernando Cóser State School of Special Education; the second was the construction of the profile of deaf and deaf students who study in the municipality; the third is the assessment of students' impressions of the digital game "CartoCon: Our Geographic Expedition" through the qualitative approach. The results obtained were positive, showing that the digital game, when adapted to the students' conditions, is a viable resource in the inclusive teaching of School Cartography, meeting the demands of the students who are part of the deaf community of the municipality.
\end{abstract}

Keywords: Geography teaching. Inclusive School Cartography. Digital game.

\title{
Resúmen
}

Les nouvelles méthodologies de l'enseignement de la géographie recherchent des propositions modernes d'approximation entre les communautés qui composent la société, ce que l'on appelle classiquement l'éducation inclusive. En ce sens, la recherche présentée ici visait à contribuer à l'amélioration des techniques d'enseignement et d'apprentissage de la cartographie scolaire des élèves sourds et sourds de la municipalité de Santa Maria, RS. La méthodologie employée a été structurée en trois phases: la première, dans l'observation des élèves de l'École d'éducation spéciale Dr. Reinaldo Fernando Cóser; la seconde était la construction du profil des étudiants sourds et sourds qui étudient dans la municipalité; le troisième est l'évaluation des impressions des étudiants sur le jeu numérique «CartoCon: notre expédition géographique» à travers l'approche qualitative. Les résultats obtenus ont été positifs, montrant que le jeu numérique, une fois adapté aux conditions des élèves, constitue une ressource viable dans l'enseignement inclusif de la cartographie scolaire, répondant ainsi aux demandes des élèves appartenant à la communauté des sourds de la municipalité.

Mots-clés: Enseignement de la géographie. Cartographie scolaire. Jeu numérique. Étudiants sourds. Malentendants.

\section{Introdução}

Ao compreender os efeitos espaciais da ação humana, assim como os modos pelos quais as características do espaço afetam e transformam os seres humanos, a Geografia revela-se como um instrumento formativo politicamente fecundo. Para formar cidadãos aptos a entender e interagir ativamente com a realidade, é fundamental ir ao encontro dos alunos, seja nas escolas regulares, ou nas escolas de educação especial, buscando democratizar conteúdos e propostas de ensino, além de produzir ferramentas pedagógicas inclusivas e contemporâneas. 
Para compreender a sociedade, é preciso entender sua estrutura, seus agentes, suas comunidades, e para o Ensino de Geografia, isso significa considerar os alunos e suas particularidades, pois só assim, efetivar o processo de inclusão escolar. Complementando essa perspectiva, Rodrigues (2017, p. 1) diz que a inclusão escolar é um processo de "aprendizado e aperfeiçoamento da educação, pois nela os agentes modificam-se e se transformam em prol do desenvolvimento de habilidades e técnicas para que o conhecimento seja proporcionado coletivamente".

Isto posto, a pesquisa teve como objetivo geral investigar as possibilidades oferecidas pelos jogos digitais como ferramentas no processo de alfabetização cartográfica de alunos surdos e deficientes auditivos do município. Adotou-se também os seguintes objetivos específicos: a) auxiliar os alunos surdos e deficientes auditivos a compreender os conteúdos relevantes no processo de alfabetização cartográfica fazendo uso de um ambiente digital; b) elaborar um jogo digital com conteúdo de Cartografia Escolar utilizando a Língua Brasileira de Sinais; c) avaliação do jogo digital "CartoCon: Nossa Expedição Geográfica". Com isso, definiu-se as estratégias de observação e intervenção nas turmas de alunos surdos e deficientes auditivos da Escola Estadual de Educação Especial Dr. Reinaldo Fernando Cóser.

Inicialmente o artigo apresenta em sua fundamentação teórica, referências que vão desde a Cartografia Escolar e suas transformações com pesquisas sobre Cartografia Inclusiva, ao uso dos jogos digitais como ferramentas pedagógicas. Após, chega-se aos procedimentos metodológicos, onde apresentam-se e referenciam-se as etapas metodológicas sob a perspectiva do método científico indutivo (na observação do público-alvo), nas abordagens quantitativa (construção do perfil dos alunos), e na qualitativa (na apreciação e aprendizagem dos alunos ao utilizar o jogo digital). Em seguida apresenta-se as etapas da construção do jogo digital educacional e tridimensional "CartoCon: Nossa Expedição Geográfica", desde as observações teóricas seguidas pela realização prática, com o emprego de softwares e a criação dos vídeos em Libras. Por fim, chega-se aos resultados e às discussões da pesquisa, com a finalização do jogo digital, a participação ativa dos alunos e a aprendizagem.

\section{Fundamentação teórica}

Do passado mais longínquo aos dias atuais, a Cartografia se transformou, deixando os imprecisos rabiscos, retratados por nossos antepassados, para ascender como ciência. Hoje é um dos mais importantes campos da Geografia. Contemporaneamente, os produtos cartográficos vêm percorrendo diferentes instâncias científicas e pedagógicas, que a exemplo desta pesquisa, esteve presente nas atividades próprias para a alfabetização cartográfica dos alunos da comunidade surda santamariense.

Muitos teóricos influenciaram na evolução e coerência da Cartografia Escolar no modelo que temos hoje. Simielli (1986), por exemplo, trouxe em pauta a questão das habilidades desenvolvidas pelo ensino da Cartografia Escolar, como a lateralidade e a orientação espacial. De acordo com a autora, a utilização de variados referenciais de 
orientação espacial estrutura o processo de alfabetização cartográfica, explora e desenvolve uma gama de aspectos cognitivos da criança. Esta reflexão, por sua vez, influenciou a elaboração dos Parâmetros Curriculares Nacionais de Geografia (1998), que definiram a Cartografia Escolar como uma área transformadora na perspectiva espacial dos alunos, sendo nela aplicável, inclusive, os temas transversais, em especial, a pluralidade cultural, orientação sexual, meio ambiente, saúde (com a Geografia da Saúde), e trabalho e consumo. Nesse contexto, a Cartografia Escolar passa a significar muito mais que uma técnica da representação voltada para a leitura e a explicação do espaço, ela se torna um veículo de comunicação com os alunos.

Outros autores também contribuíram para a Cartografia Escolar, como Castrogiovanni \& Costella (2006) ao abordarem a alfabetização espacial expressa na relação entre o brincar e o cartografar; Almeida \& Passini (1994, p. 9) ao afirmarem que a educação para leitura de mapas precisa ser entendida como "o processo de aquisição de um conjunto de conhecimentos e habilidades", para que os alunos consigam efetuar a leitura do espaço, representa-lo e dessa forma construir os conceitos às relações espaciais; e Martinelli (1991; 2003; 2006), ao versar sobre as aplicabilidades da Cartografia Temática e seu ensino no contexto escolar. Em linhas ainda mais contemporâneas, em convergência com as metodologias de Ensino de Geografia e Inclusão Escolar, encontramos pesquisas relacionadas majoritariamente ao atendimento de alunos cegos ou com deficiência visual, mas que evidenciam a consolidação do movimento em prol da inclusão como, por exemplo, Jordão (2015) e sua dissertação sobre Cartografia Tátil; Ventorini \& Silva (2018) e o uso de maquetes para o ensino cartográfico com alunos cegos; Freitas (2017), com a intersecção da Cartografia Escolar Inclusiva entre a escola, comunidade e universidade; e Almeida et al. (2018) apresentando algumas abordagens da Cartografia Inclusiva através de experiências com a Cartografia Tátil, a Etnocartografia e no mapeamento participativo nas escolas. Isto posto, é neste sentido que a pesquisa aqui apresentada interage, na contribuição ao processo de transformação e renovação da Cartografia Escolar se utilizando, para isso, da proposição dos jogos digitais como ferramenta e estratégia de ensino.

Atualmente, discute-se muito sobre as "novas tecnologias da educação", onde os jogos digitais e a gamificação se encontram. A tecnologia é tida como o conjunto de conhecimentos e princípios científicos que se aplicam ao planejamento, construção e utilização de equipamentos eletrônicos em um determinado tipo de atividade (Kenski, 2012). Inseridos nesse contexto, os softwares educativos tomam forma e são reconhecidos e utilizados por muitos professores como uma ferramenta pedagógica, graças às constantes evoluções, tanto na quantidade de produções, quanto na qualidade, postos à disposição das escolas. Com isso, muitos professores/pesquisadores têm empregado técnicas de informática em suas práticas pedagógicas, e com isso, formulam teorias sobre a validade de tais técnicas aplicadas ao ensino. Essa realização prática é o resultado de árduo trabalho e do envolvimento de muitos profissionais, educadores, técnicos e artistas, que juntos buscam a democratização, contemporaneidade e humanização destas ferramentas, principalmente para que elas não se tornem obsoletas a 
curto prazo, e que não sejam efêmeros objetos de interação, buscando integrar os alunos em diferentes realidades sociais.

Os jogos digitais podem apresentar diversas possibilidades de interação, em variados recursos e atividades em consonância com storyboard ${ }^{l}$ planejado. Não obstante, os jogos digitais educacionais voltados ao Ensino de Geografia tem algo a mais para oferecer: o cenário. Nele podem-se representar o espaço em diversas escalas e com perspectivas diferenciadas. Um bom exemplo disso, são os cenários tridimensionais que podem se aproximar da veracidade de um espaço real, possibilitando aos alunos interagir com simuladores da realidade, com personagens, carros, árvores, entre outros, configurando uma paisagem efetivamente existente. Nesta modalidade, também é possível integrar conhecimentos teóricos e práticos no formato de atividades que encaminhem o aluno a um objetivo final específico, podendo estar acompanhado de gratificação ou valorização de desempenho. No caso do jogo "CartoCon: Nossa Expedição Geográfica", reuniu-se todos estes elementos mencionados, projetando como cenário, o recorte devidamente delimitado do centro de Santa Maria, RS.

Outra característica relevante dos jogos digitais, quando aplicados coletivamente em aula, é a capacidade de socialização entre os alunos, que passam a dialogar em busca de soluções aos problemas apresentados nas atividades. O jogo CartoCon, por exemplo, motivou os alunos a buscarem, de forma conjunta, a resolução das questões apresentadas, discutindo inclusive, os sinais em Libras apresentados nos vídeos como meio de comunicação. Para Cezar (2009, p.33) este recurso se torna uma "atividade lúdica do ser social", e conclui que a socialização é um aspecto importante dos jogos enquanto ferramentas de aprendizagem, pois "o confronto de diferentes pontos de vista, essencial ao desenvolvimento do pensamento lógico, está sempre presente no jogo". Com isso, oportunizam novas experiências de imersão em outras realidades (quando o jogo reproduz um espaço real) e a vivenciar diferentes identidades, ocorrendo assim, o aprendizado de competências e conhecimentos associados às identidades dos personagens dos jogos (Hsiao, 2007). Assim, de acordo com Savi \& Ulbricht (2008) o jogo ou simulador em que o aluno coordene as ações de um personagem enfrentará os mesmos dilemas e assimilando conteúdos e conhecimentos relativos às suas atividades.

Há ainda de ser considerado, como não poderia deixar de ser, o aspecto cognitivo dos jogos digitais. Segundo Tarouco (2008), eles proporcionam a melhoria da flexibilidade cognitiva (com o aprendizado de novas informações e conteúdo), e contribui no exercício mental que estimula a formação de conexões neurais e modifica o estado reflexivo mediante a exigência de concentração. Dessa forma, os jogos educacionais tendem a instigar a busca por resoluções, ao mesmo tempo em que ensina sobre um conteúdo específico, e com isso, torna-se uma forma interessante para a evitação de repostas e soluções mecânicas, que por vezes são o resultado de um ensino antiquado e individualista. Assim, os jogos proporcionam o desenvolvimento intelectual, pois para vencer os desafios apresentados, o jogador precisa elaborar estratégias e

\footnotetext{
${ }^{1}$ Esboço sequencial de uma narrativa. Serve no planejamento do enredo em jogos, filmes, comerciais, ou quaisquer outras atividades que necessitem "contar algo" ao espectador ou jogador.
} 
compreender como os diferentes elementos do jogo relacionam-se (GROS, 2003), e com isso, desenvolvem habilidades cognitivas, como a resolução de problemas, reconhecimento de padrões, tomada de decisão, processamento de informações, criatividade e pensamento crítico.

Os jogos digitais já são amplamente utilizados em diferentes níveis de ensino havendo, inclusive, jogos que aprofundam o estudo em linguagem e lógica, que como bem lembram Savi \& Ulbricht (2008), auxiliam as crianças que se encontram em processo de alfabetização ou não sabem ler, ao mesmo tempo em que ajudam no desenvolvimento da coordenação motora com o uso do mouse e teclado. No caso do jogo CartoCon, ao trabalhar a Língua Brasileira de Sinais, contribui-se com a construção da própria língua, que não possui uma estrutura convencionada de sinais próprios para o Ensino de Geografia. Apresentando também, a língua portuguesa ao aluno que optar por outra forma de comunicação.

Por fim, Savi \& Ulbricht (2008, p. 9) dizem que os jogos educacionais bem "projetados podem ser criados e utilizados para unir práticas educativas com recursos multimídia em ambientes lúdicos a fim de estimular e enriquecer as atividades de ensino e aprendizagem". Desta forma, a aplicação de jogos representa extrapolar as barreiras do ato de jogar apenas como diversão, utilizando-as como ferramentas de aprendizagem. Tal fato permite a articulação de conhecimentos tecnológicos e geográficos de forma lúdica e interativa, buscando a relação entre o ensino e a aprendizagem significativa.

\section{Procedimentos metodológicos}

Norteando-se no que foi apresentado por Rodrigues et al. (2018), esta pesquisa apoiou-se no método indutivo e nas abordagens qualitativa e quantitativa nas fases metodológicas descritas a seguir. Contudo, a pesquisa não se baseou estritamente em avaliar e compreender a comunidade surda de Santa Maria e o aprendizado dos alunos, mas também a concretização de um jogo digital, o qual também está descrito.

$\mathrm{Na}$ primeira fase da pesquisa, apoiado no método científico indutivo que, segundo Suertegaray (2005, p.15) constitui-se em "um método histórico, genéticoindutivo, ou seja, parte da observação induz leis de coexistência e de sucessão e deduz fatos novos que escapam à observação direta". Desta forma, realizamos uma atividade de campo em que observamos alunos da Escola Estadual de Educação Especial Dr. Reinaldo Fernando Cóser. Essa atividade ocorreu entre os meses de março e novembro, do ano de 2017, com uma turma de sexto ano, uma de sétimo ano, uma de oitavo, uma do nono e outra do primeiro ano do ensino médio, durante as aulas de Geografia, no turno da manhã. O objetivo foi conhecer os alunos para preparar as etapas seguintes da pesquisa, ao mesmo tempo em que nos familiarizávamos com a sua forma de comunicação.

$\mathrm{Na}$ segunda fase, utilizamos a abordagem quantitativa apresentada por Rodrigues et al. (2018, p. 84) "a transposição de acontecimentos em dados numéricos, como as plantações em um território, seus recursos naturais, a saúde de uma população, 
ou outras características de uma sociedade". Assim, adotou-se esta estratégia para a construção do perfil dos alunos surdos e deficientes auditivos que estudam no município. Os dados específicos dos alunos foram obtidos junto aos dois principais órgãos administrativos atuantes no município, a Secretaria Municipal de Educação (SMEd) e a Oitava Coordenadoria Regional de Educação $\left(8^{\circ} \mathrm{CRE}\right)$. A própria escola, onde a investigação foi realizada, forneceu informações numéricas relativas aos alunos, especificando sexo, idade, nível de escolaridade, se residente ou não em Santa Maria, se surdo ou deficiente auditivo.

$\mathrm{Na}$ terceira fase, ao fazer uso da abordagem qualitativa como embasamento para a avaliação das impressões dos alunos em relação ao jogo digital. Esta abordagem, segundo Triviños (1987), estuda os dados buscando seu sentido, tendo como base a percepção do fenômeno dentro do seu contexto, e que, portanto, no uso da descrição qualitativa, procura-se adquirir e captar não apenas o aspecto visível do fenômeno, como também a subjetividade. Nesse sentido, utilizamos um questionário que abordou aspectos de aprendizagem cartográfica e a adequação técnica do jogo, como manuseio, comandos e a existência de erros gráficos conhecidos como "bugs". Cabe ressaltar também que alguns alunos em estágio incipiente de alfabetização em Libras não compreenderam totalmente os aspectos envolvidos na atividade do jogo.

\section{A elaboração do jogo digital 3D}

A elaboração do jogo exigiu grande variedade de informações geográficas, cartográficas e culturais. A primeira etapa envolveu a delimitação da área a ser digitalizada para compor o cenário. Assim, a escolha do recorte espacial onde o jogo se desenvolve teve observância na proposta de Rodrigues et al. (2019, p. 206), em que forma definidos cinco aspectos norteadores: 1) Pontos de referência importantes culturalmente, como teatros, museus, praças, locais de comércio, restaurantes, entre outros; 2) Relações de afetividade entre a população local e o lugar - incluindo a população a quem o jogo se destina; 3) Reconhecimento fácil dos elementos, de modo que mesmo aqueles que não tivessem conhecimento prévio da área pudessem identificar objetos característicos a partir da interação com o jogo; 4) Espaço com elementos que facilitassem a mobilidade fluída através dos percursos, como ruas amplas e locais com circulação de pessoas; 5) Liberdade em todas as direções, para que o jogador pudesse explorar os quatro pontos de orientação geográfica.

Com isso, pudemos eleger, seguindo os quatro principais pontos cardeais, os seguintes locais: o Theatro Treze de Maio, localizado na Praça Saldanha Marinho, no nordeste da região delimitada, e onde o jogo se inicia; o Museu Educativo Gama D'Eça, administrado pela Universidade Federal de Santa Maria e criado em 23 de julho de 1968, na gestão do reitor José Mariano da Rocha Filho. Localiza-se a sudeste e é um local de forte apreço cultural e educacional para o município; a Praça Saturnino de Brito, localizada ao sudoeste, que faz divisa com a Rua Coronel Niederauer de um lado, e de outro com a Rua Dr. Bozano, considerada um ponto de lazer e encontros por diversos grupos de Santa Maria; e por fim, a Catedral Metropolitana de Santa Maria, localizada 
no Noroeste. A Figura 01 apresenta os pontos e a área digitalizada, assim como as distâncias reais entre os pontos.

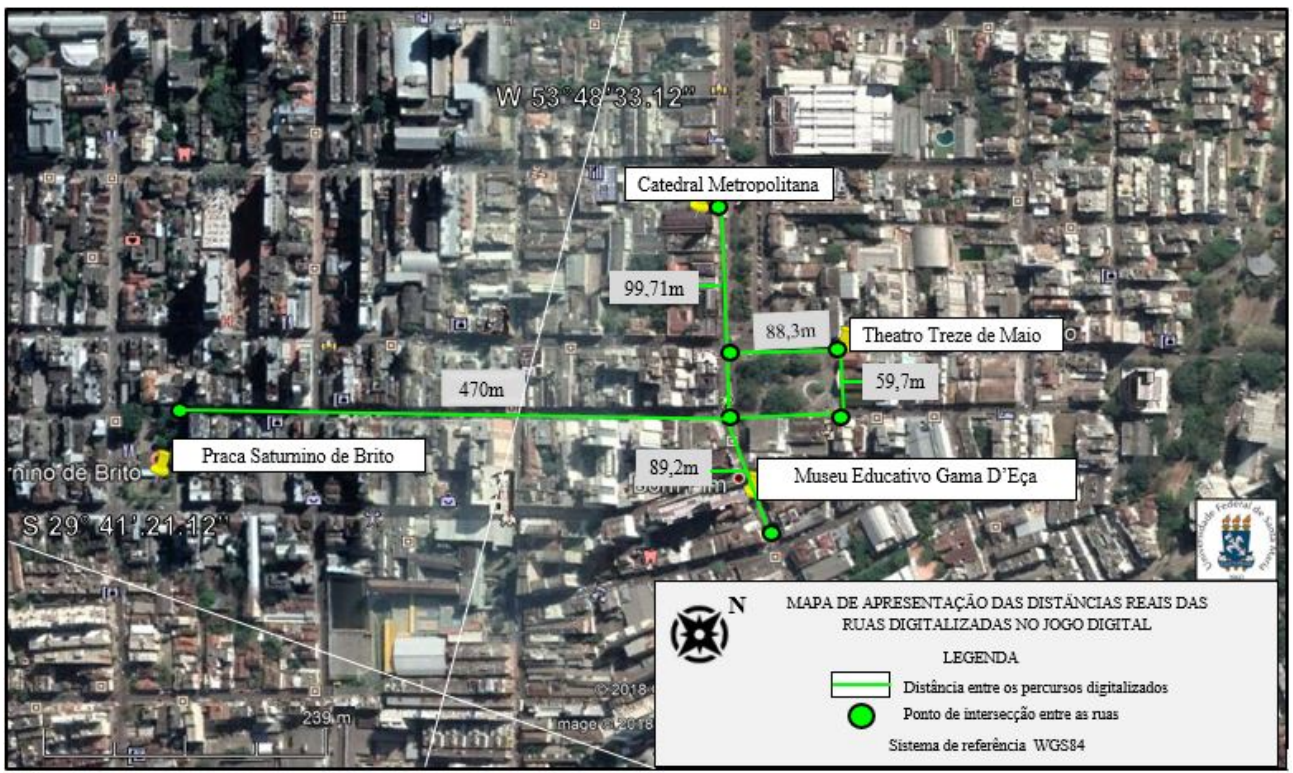

Figura 01: Mapa dos pontos e ruas digitalizadas no jogo digital. Fonte: Google Earth Pro (2018), adaptado pelos autores (2019).

Na etapa seguinte, definimos os conteúdos que seriam trabalhados no jogo. Tomamos as sugestões dos PCN's como ponto de partida. Para eles, o aprendizado desejado envolve os conteúdos cartográficos vistos como instrumentos de apreciação do espaço e das relações da sociedade com a natureza, nos quais estariam implicadas habilidades de leitura, compreensão e criticidade sobre as informações apresentadas nos mapas.

Foram definidas um total de quinze atividades desenvolvidas durante o jogo, e uma atividade final denominada "Monte seu Mapa". Tais atividades foram planejadas de forma que atendessem às instruções básicas quanto aos conteúdos pertinentes à alfabetização cartográfica, objetivando o amadurecimento das habilidades espaciais dos educandos. Nesse sentindo, ler e interpretar as representações cartográficas foram consideradas as metas do trabalho. Para tanto, apoiamo-nos nas observações realizadas nas turmas durante as aulas de Geografia e questionamos a professora da classe sobre os conteúdos que foram mais bem entendidos pelos alunos no ensino de Cartografia Escolar. Desse modo, classificamos o nível de dificuldade dos principais conteúdos, para que assim pudéssemos saber o quanto poderíamos aprofundá-los nas atividades, dando uma orientação geral para a organização das questões trazidas no jogo. 
Durante a construção das atividades, observamos que seria adequada a criação não apenas das quinze atividades, mas também a elaboração de questões que pudessem compor um banco de dados na plataforma. A ideia foi que cada jogador pudesse desfrutar de novas atividades a cada nova jogada, possibilitando novas reflexões e resoluções de problemas. Assim, elaboramos um total de cinquenta exercícios que percorrem os conteúdos cartográficos sob diferentes formas de apresentação. A cada nova jogada, a plataforma faz uso do banco de dados e aplica o exercício aleatoriamente entre as quinze atividades do jogo.

A atividade intitulada "Monte Seu Mapa" foi concebida com o objetivo de reunir os conceitos e conteúdos trabalhados ao longo do jogo, razão pela qual foi apresentada ao final das demais atividades. Nela o aluno pode montar um mapa de localização de Santa Maria ou de seus municípios lindeiros, sendo possível também personalizá-los. Colocamos à disposição os recortes dos seguintes municípios: São Martinho da Serra, Itaara, Júlio de Castilhos, Silveira Martins, São João do Polêsine, Restinga Sêca, Formigueiro, São Sepé, São Gabriel, Dilermando de Aguiar e São Pedro do Sul.

Durante o percurso do jogo, em que a movimentação do personagem ocorre através do Cursor Control Keys, as atividades previamente programadas foram apresentadas por meio de um objeto, uma moeda dourada, que quando ativada apresenta o exercício cartográfico. Assim, o jogo envolve os seguintes conteúdos: orientação, escala, coordenadas geográficas (com pontos marcados e apresentados nos locais finais de percurso) e acesso a representações (carta, mapa e planta). A carta apresentada é a de Camobi (folha SH.22-V-C.2; MI-2965/2; escala 1:50.000), com o recorte da delimitação por onde o educando percorrerá o trajeto.

Estando em acordo com o contexto da gamificação (Fardo, 2013; Costa \& Marchiori, 2016), não poderia faltar a utilização de pontos e conceitos próprios dos jogos digitais, que estimulam a competitividade e o interesse de autossuperação. Para tanto, elaboramos um ranking que atribui títulos por meio dos resultados de cada jogador, com base em um cálculo que considera o número de acertos e a quantidade de tempo que o aluno levou para responder cada questão. Os exercícios não respondidos não são contabilizados. A seguir, apresentamos na Figura 02 os respectivos títulos de pontuação:

Até 100 pontos finais o educando ganhará o título "Cartógrafo Local" De 100 a 150 pontos finais o educando ganhará o título "Cartógrafo Global" De 150 a 200 pontos finais o edıcando ganhará o título de "Sábio Cartógrafo" De 200 a 500 pontos para cima o educando ganhará o título de "Senhor da Cartografia"

Figura 02: Sistema de pontos e títulos do jogo.

Na etapa seguinte, seguimos para a tradução das atividades. Esta fase foi uma das mais dispendiosas em relação ao tempo de execução, pois foram necessários 
aproximadamente dois meses para realizar a tradução das atividades de língua portuguesa para a Língua Brasileira de Sinais, quando fizemos uso da datilologia, utilizando o alfabeto gestual, além de criar sinais específicos para algumas palavras.

Decidimos utilizar vídeos como forma de explicar e introduzir as atividades do jogo. Foi necessário experimentar a comunicação com o uso SignWritin²; entretanto, enfrentamos dificuldades ao tentar expressar sinais em sua forma escrita, pois a Libras não dispõe de um conjunto de sinais padronizados e consensuais para o ensino de Geografia. Ao estabelecermos imagens para explicar um conteúdo, presenciamos diversas lacunas que exigiriam uma pesquisa particular em relação à língua e a proposta de novos sinais, o que por sua vez demandaria um cuidado maior e uma aprovação de outras pessoas da comunidade surda e deficientes auditivos.

Durante cinco semanas realizamos a gravação dos vídeos3, fazendo uso de uma tela azul escura, e uma iluminação dupla, natural e artificial, garantindo uma boa qualidade de imagem para a gravação dos vídeos, além do uso da câmera profissional Nikon CoolPix P900. O enquadramento da câmera buscou condizer com o espaço de realização dos sinais em Libras. Segundo Quadros (1997, p. 49), "as sentenças gramaticais ocorrem dentro de um espaço definido, na frente do corpo, em uma área limitada pelo topo da cabeça e que se estende até os quadris".

A seguir apresentamos, na Figura 03, o espaço necessário para a comunicação em Libras. A primeira imagem foi desenvolvida por Langevin e Ferreira Brito (1988), e a segunda é um registro do enquadramento para a gravação dos vídeos elaborados para traduzir as atividades do jogo digital, de forma que houvesse o espaçamento ideal para a execução dos movimentos na realização dos sinais.
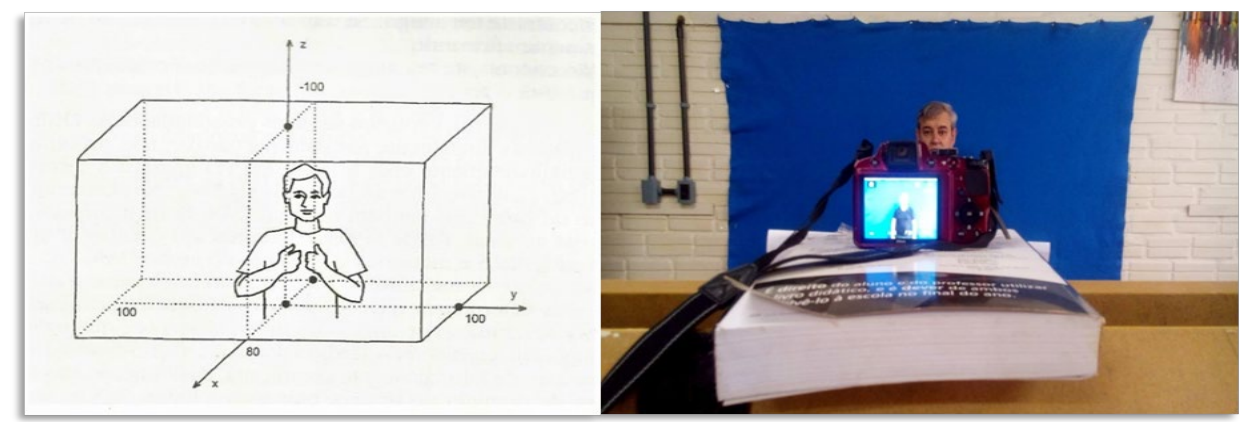

Figura 03: Espaço de realização de sinais em Libras.

Fonte: Langevin e Ferreira Brito (1988, p.1) apud. Quadros, R. M. (1997, p. 49), adaptado pelos autores (2019).

Para a confecção do jogo, usamos softwares especializados para cada procedimento de confecção de jogos digitais. O primeiro deles foi o programa Blender,

2 Forma escrita da Língua Brasileira de Sinais 
utilizado para a modelagem de objetos e áreas em terceira dimensão (3D). Com ele, foram concebidos os modelos tridimensionais do Theatro Treze de Maio, o Museu Educativo Gama D'Eça e os personagens. O Blender é um software de criação em 3D gratuito para Windows, Linux e Mac, de código aberto que oferece um ambiente com recursos avançados. Com ele, o usuário pode criar projetos simples, como modelos de produtos e maquetes, e até alguns mais complicados, como animações e jogos. O programa disponibiliza também uma variedade de ferramentas que podem ser utilizadas para criar personagens (com muita riqueza de detalhes, usando o recurso Sculpting), podendo também criar modelagens a partir de superfícies.

O programa Google Earth Pro esteve presente na segunda etapa para compor o cenário, pois através do recurso Street View é possível coletar imagens no percurso prédeterminado pelo software. O software AutoCAD Map $3 D$ foi responsável pela construção das plantas baixas de dois pontos relevantes, o Theatro Treze de Maio e o Museu Educativo Gama D'eça, para que a partir deles pudesse ser construída a modelagem tridimensional aplicada ao jogo. Por último, utilizamos o software Unity (versão 2017) para a montagem e compilação dos elementos do jogo, ou seja, o ambiente que integralizou todos os objetos construídos nas plataformas anteriores. O programa encontra-se disponível para download nas versões livre (com algumas limitações) e por assinatura, com os recursos completos. O programa é chamado também de Build Standalone, o que significa que o jogo é gerado independentemente do usuário dispor ou não do programa Unity pré-instalado em seu computador. É importante destacar que o programa executa apenas no sistema Windows, não estando disponível em outros sistemas operacionais, como Linux e Mac OS.

\section{Resultados e discussões}

Acerca do perfil dos alunos, de acordo com as informações fornecidas pela escola Dr. Reinaldo Fernando Cóser, estavam matriculados na ocasião o total de 78 (setenta e oito) alunos. Desses, foi registrado um total de 44 (quarenta e quatro) alunos com deficiência auditiva, sendo vinte e duas alunas do sexo feminino, e vinte e dois alunos do sexo masculino. As idades desses alunos variavam entre cinco anos, no curso de educação para deficientes auditivos, e quarenta e nove anos, no curso do EJA.

Como resultado das observações de campo realizadas na Escola Dr. Reinaldo Fernando Cóser, percebemos que os alunos acompanhavam com certa dificuldade os conteúdos presentes nos livros didáticos, e que quando atentos às explicações do professor, em Língua Brasileira de Sinais, conseguiam compreender melhor. Entretanto, registramos que houve uma dificuldade do docente em encontrar termos para alguns temas importantes, no contexto do vocabulário da Geografia em geral, e da Cartografia em particular. Nem todas as palavras em língua portuguesa foram ainda concebidas em Libras, sendo necessária, por vezes, uma adaptação informal de termos.

Outra questão importante foi que parte dos alunos, segundo a professora da classe, não se sentiram motivados em realizar tarefas escolares em casa. Pode parecer algo comum nas escolas, mas cabe destacar que no contexto da educação especial, em 
que pode haver maior necessidade de mediação docente, a existência de poucos recursos didáticos e meios de comunicação acessíveis pode afetar sobremaneira tarefas de pesquisa e outras atividades.

Observamos também o que pareceu ser uma tendência mais pronunciada a dispersão da atenção dos alunos surdos durante as aulas, quando comparados aos alunos com deficiência auditiva. Estímulos periféricos do ambiente pareciam ser mais atrativos aos alunos do primeiro grupo. A relação entre déficits sensoriais específicos e a resposta de aprendizagem nos pareceu um campo de investigação pertinente para novas pesquisas no contexto das ferramentas pedagógicas inclusivas.

O nome do jogo, CartoCon, surgiu da união das palavras Cartografia e Conexões. Ambas representam o objetivo central do jogo, que é a proposta de integração entre aprendizado, inclusão e Cartografia Escolar, mediante recursos e conteúdos abordados no ambiente digital. O subtítulo do jogo, "Nossa Expedição Geográfica", visa expressar a concepção de que o usuário não está necessariamente sozinho em sua campanha no ambiente.

Foram criados dois personagens, cada qual de um gênero. Inicialmente tínhamos como proposta a possibilidade de que os alunos confeccionassem seus próprios personagens, conforme as características fenotípicas de interesse; contudo, para que isso fosse possível, seria necessário incluir um grande número de atributos na base de programação do jogo, o que o tornaria ainda maior e mais pesado para transferir e abrir nos computadores. Considerando que as escolas não renovam as máquinas com frequência, e muitas sequer possuem laboratórios de informática, não optamos por esse caminho. Para representar o movimento humano próprio do cenário urbano, utilizamos recursos variados, como personagens caminhando pelas ruas, nos pontos de coleta dos fragmentos do globo dourado, carros e o impacto das correntes de ar expressa no movimento das folhas das árvores e das nuvens. Consideramos importante colocar elementos de orientação e referências que ficaram presentes no transcorrer do jogo, a exemplo do marcador de tempo, as instruções, a pontuação, os fragmentos do globo dourado que foram coletados, o mapa, a orientação por meio da rosa dos ventos, e também o indicador do nível - expertise - em que o jogador se encontra. A Figura 04 apresenta a introdução do jogo, após a etapa de seleção de idioma, em que podem ser escolhidas as opções Libras, Língua Portuguesa ou Língua Inglesa. 


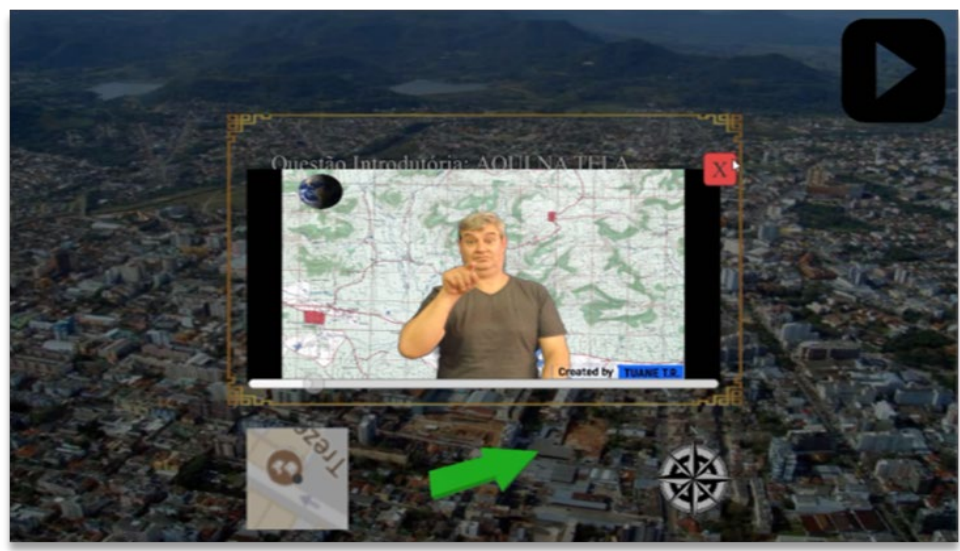

Figura 04: Tela inicia do jogo digital, apresentação da questão introdutória. Fonte: dos autores (2019).

A seguir, apresentamos na Figura 05 parte do cenário do jogo digital. Nele é possível ver como ficou a digitalização da Praça Saldanha Marinho, em especial, objetos como o Chafariz e o Coreto.

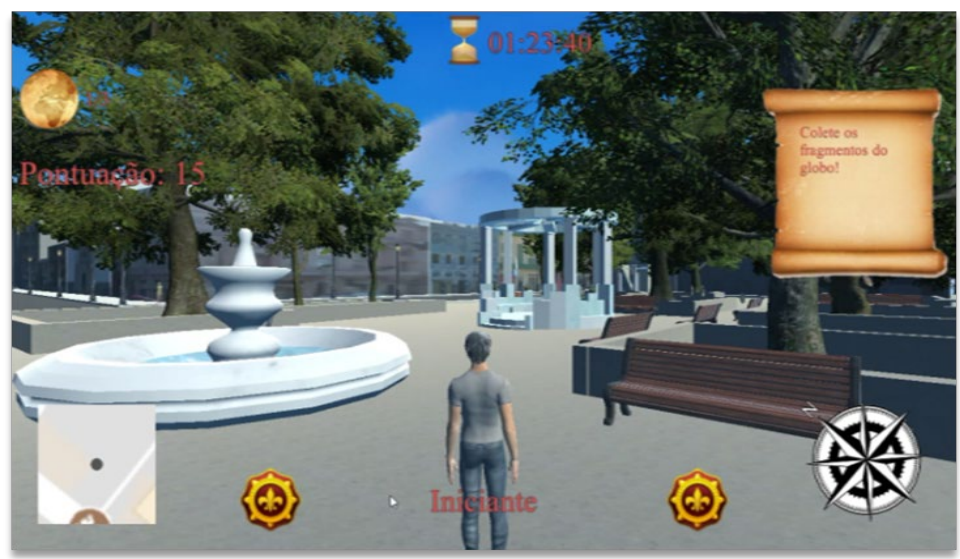

Figura 05. Apresentação do jogo finalizado. Fonte: autores (2019).

O primeiro contato dos alunos com o jogo foi positivo. Houve atitudes de animação e boas expectativas na turma. A nossa primeira preocupação foi quanto ao reconhecimento do município, para validar a estética do jogo e os recursos de construção do cenário. Recebemos, então, a seguinte avaliação dos alunos: dos vinte e três (23) alunos participantes, apenas três (3) não reconheceram o município. Quando questionados a respeito, disseram que não residiam em Santa Maria. Logo, o cenário 
conseguiu representar bem os aspectos reais, sendo reconhecido por 78,3\% dos discentes.

Outro aspecto foi a manipulação dos comandos, o saber iniciá-lo e a jogabilidade. Observamos que quatro (4) alunos tiveram dificuldades em abri-lo. Quanto aos comandos de execução de movimentos, não houve registro de dificuldades. Após uma breve explicação sobre as teclas envolvidas, conseguiram jogar com fluidez e coordenar bem os movimentos dos personagens - pular, caminhar, correr, lateralizar. A Figura 06 mostra um aluno surdo manuseando o jogo digital:

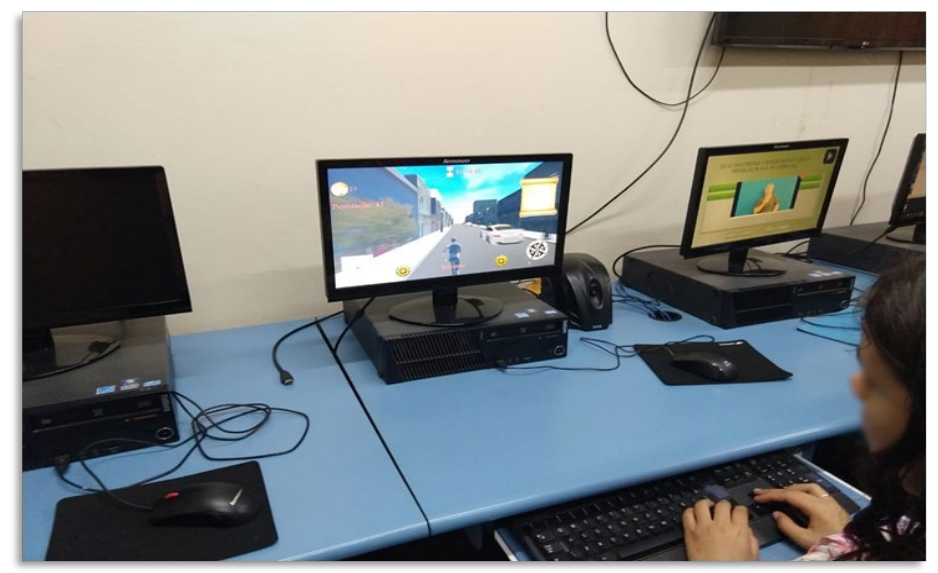

Figura 06: Aluno jogando o CartoCon. Fonte: Autores (2019).

A Figura 07 mostra a turma de oitavo ano reunido no laboratório de informática da escola para testar o jogo digital:

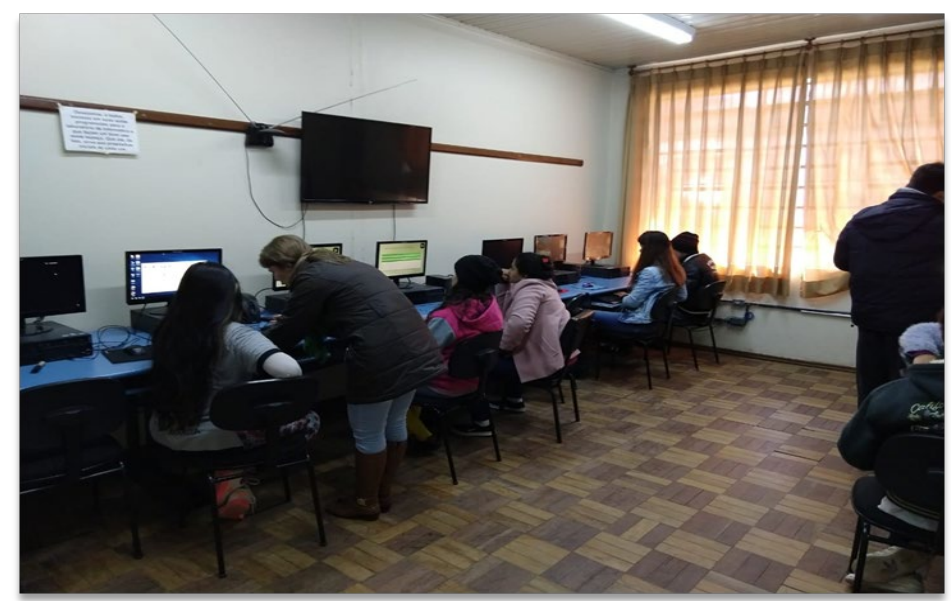

Figura 07: Turma reunida para jogar o CartoCon. Fonte: Autores (2019). 
Por fim, concluímos que jogo digital se mostrou uma boa ferramenta para a alfabetização cartográfica de alunos surdos e deficientes auditivos, e para a aprendizagem de Geografia no contexto escolar em dois níveis de ensino, fundamental e médio. Com isso, o jogo mostrou-se uma opção pertinente para a realização de práticas sobre os conteúdos cartográficos.

O jogo mostrou-se também um recurso de interesse para os alunos, talvez por ser uma ferramenta diferente de práticas convencionais em sala de aula, como as maquetes. Entretanto, evidentemente não deve ser encarado como um recurso inteiramente substitutivo de outras formas de aprendizado. Diferentes técnicas podem despertar a curiosidade em diferentes alunos, e diferentes estratégias de ensino são importantes. O jogo digital "CarCon: Nossa Expedição Geográfica" é um recurso complementar que pode potencializar o amadurecimento cognitivo dos alunos, por ser alinhado às novas formas com as quais os alunos interagem com os seus ambientes.

Assim, a aprendizagem dos alunos sobre a importância da Cartografia Escolar para o Ensino de Geografia e as possibilidades de mapeamento, bem como suas interpretações, foram compreendidas pelos alunos ao utilizarem o jogo digital. Com a utilização do jogo digital, evidenciaram-se os benefícios destacados por Savi \& Ulbricht (2008) quanto ao efeito motivador na facilitação da aprendizagem, no desenvolvimento de habilidades cognitivas, na experiência de nova identidades e na socialização e coordenação motora. Com isso, houve a proximidade entre teoria e prática no ensino e na aprendizagem, do que hoje podemos chamar de Cartografia Escolar Inclusiva.

\section{Considerações finais}

Esta pesquisa, situada no campo do Ensino de Geografia, visou dar visibilidade à Língua Brasileira de Sinais e contribuir com o desenvolvimento de recursos tecnológicos voltados à educação, possibilitando a melhoria do apoio didático ao professor e uma melhor experiência de aprendizagem para os alunos. A experiência foi enriquecedora, possibilitando-nos ver o mundo sob novas perspectivas, fazendo-nos pensar sobre o caráter multifacetado da realidade, o papel do professor e a construção de um modelo de educação democrática.

Quanto à leitura e à apreciação do lugar, percebemos que os alunos residentes ou apenas turistas no centro de Santa Maria/RS conseguiram identificar os elementos presentes no cenário e suas impressões topológicas. Isso ficou claro ao acompanharmos os estudantes da escola onde foi aplicado o jogo, quando manifestaram suas impressões uns com os outros. Alguns alunos não conheciam o lugar, mas isso não impediu a interação com o ambiente, pois demonstraram interesse em jogar e conhecer os locais.

Há, entre os professores e pesquisadores, cada vez mais discussões sobre a Cartografia no contexto escolar. Isso propicia a concepção de novas teorias e práticas em benefício de uma educação crítica, atendendo às demandas contemporâneas. 


\section{Referências bibliográficas}

ALMEIDA, R. D. de. E PASSINI, E. Y. O espaço geográfico e suas representações. São Paulo: Contexto, 1994.

ALMEIDA, R. A.; SENA, C. C. R. G.; CARMO, W. R. do. Cartografia inclusiva: reflexões e propostas. Boletim Paulista de Geografia, v. 100, p. 224-246, 2018.

BRASIL. Secretaria de Educação Fundamental. Parâmetros curriculares nacionais: geografia / Secretaria de Educação Fundamental. Brasília: MEC/ SEF, 1998. 156p.

CASTROGIANNI, A. C.; COSTELLA, R. Z. Brincar e Cartografar com os diferentes mundos geográficos: a alfabetização espacial. Porto Alegre: EDIPUCRS, 2006.

CEZAR, K. P. L. Acentolândia: criação e aplicações de um jogo de regras sobre acentuação gráfica para séries iniciais do ensino fundamental. Maringá: 2009.

CORREAA, R. L. Espaço: Um conceito-chave da Geografia. In: CASTRO, Iná et al. (org.). Geografia: conceitos e temas. Rio de Janeiro: Bertrand Brasil, 2000.

COSTA, A. C. S.; MARCHIORI, P. Z. Gamificação, elementos de jogos e estratégia: uma matriz de referência. InCID: Revista de Ciência da Informação e Comunicação, Ribeirão Preto, v. 6, n. 2, p. 44-65, set. 2015/fev. 2016.

FREITAS, M. I. C. Cartografia Escolar e Inclusiva: construindo pontes entre a universidade, a escola e a comunidade. Revista Brasileira de Educação em Geografia, Campinas, v. 7, n. 13, p. 135-157, jan./jun., 2017.

FARDO, M. L. A gamificação aplicada em ambientes de aprendizagem. Revista CINTED-UFRGS, Porto Alegre, v. 11 n 1, julho, 2013.

GONÇALVES, C. W. P. Reflexões sobre a Geografia e educação: notas de um debate. In: O Ensino da Geografia em questão e outros temas. Terra Livre: Marco Zero, ${ }^{\circ}{ }^{2}$, 1987.

KENSKI, V. M. Educação e tecnologias: Um novo ritmo da informação. $8^{\circ}$ ed. Campinas: Papirus, p. 15-25, 2012.

LANGEVIN, R.; FERREIRA BRITO, L. Negação em uma língua de sinais brasileira. Anais do XI Encontro Nacional de Lingüística. PUC/SP, 1988.

MARTINELLI, M. Curso de cartografia temática. São Paulo, Contexto, 1991. 180 p. (Coleção Manuais Contexto).

MARTINELLI, M. Mapas da Geografia e Cartografia Temática. São Paulo: Contexto, 2003.

MARTINELLI, M. O Ensino da Cartografia Temática. In: CASTELLAR, Sonia (Org.) Educação Geográfica, Teorias e Práticas Docentes. São Paulo: Contexto, 2006. 
QUADROS, R. M. de. Educação de Surdos: A Aquisição da Linguagem. São Paulo: Artes Médicas Sul Ltda. 1997.

RODRIGUES, T. T. A Cartografia Inclusiva e o Futuro no Ensino da Geografia. In: VII Congresso Internacional de Educação. 2017, Santa Maria. Anais Faculdade Palotina de Santa Maria, p. 1-8. Disponível em: <www.fapas.edu.br/rvistas/anaiscongressoie>.

RODRIGUES, T. T.; CASSOL, R.; MIRANDA, W. de O. Fundamentos cartográficos aplicados ao planejamento de ambientes digitais em jogos educacionais. Revista Brasileira de Educação em Geografia. Campinas, v. 9, n. 17, p. 199-214, jan./jun., 2019.

RODRIGUES, T. T.; CASSOL, R.; KEPPEL, M. F. O método indutivo e as abordagens quantitativa e qualitativa na investigação sobre a aprendizagem de alunos surdos. Pesquisar: revista de estudos e pesquisas em Ensino de Geografia. Santa Catarina: Florianópolis, v. 6 n. 9, p. 77-91, maio 2019.

SIMIELLI, M. E. R. O mapa como meio de comunicação: implicações no ensino de Geografia no $1^{\circ}$ grau. São Paulo, 1986. Tese (Doutorado)- FFLCH, Universidade de São Paulo.

SUERTEGARAY, D. M. Notas Sobre Epistemologia em Geografia. Florianópolis: UFSC, 2005.

JORDÃO, B. G. F. Cartografia Tátil na Educação Básica: os cadernos de Geografia e a inclusão de estudantes com deficiência visual na rede estadual de São Paulo. Dissertação de Mestrado. USP, 200p. 2015.

SAVI, R.; ULBRICHT, V. R. Jogos digitais educacionais: benefícios e desafios. Revista CINTED-UFRGS, Porto Alegre. v. 6 nº 2, dez. de 2008.

VENTORINI, S. V.; SILVA, P. A. Cartografia Tátil: a mediação de conceitos para alunos cegos. Revista Boletim Paulista de Geografia, v. 99, p. 124-141. 2018.

TAROUCO, L. M. R.; ROLAND, L. C.; FABRE, M. J. M.; KONRATH, M. L. P. Jogos Educacionais, Novas Tecnologias na Educação. CINTED-UFRGS. 2008.

HSIAO, Hui-Chun. A Brief Review of Digital Games and Learning. DIGITEL 2007, The First IEEE International Workshop on Digital Game and Intelligent Toy Enhanced Learning. Los Alamitos. Disponível em: <http://doi.ieeecomputersociety.org/10.1109/ DIGITEL.2007.3>. Acesso em 06 nov. 2019.

GROS, B. The impact of digital games in education. First Monday, v. 8, n. 7, jul. 2003. Disponível em: <http://www.firstmonday.org/issues/issue8_7/xyzgros/index.html>. Acesso em: 15 nov. 2007.

* Este artigo apresenta uma síntese da pesquisa intitulada "O jogo digital como recurso didático na alfabetização cartográfica de alunos surdos e deficientes auditivos em Santa Maria/RS, Brasil”, realizada no Programa de Pós-graduação em Geografia (PPGGeo) da Universidade Federal de Santa Maria (UFSM), e finalizada no ano de 2019. 


\section{Tuane Telles Rodrigues}

Doutoranda em Geografia no Programa de Pós-Graduação em Geografia (PPGGeo) da Universidade Federal de Santa Maria (UFSM). Endereço postal: Departamento de Geografia e Geociências, Centro de Ciências Naturais e Exatas, Universidade Federal de Santa Maria. Caixa Postal 97105-900, Santa Maria, RS, Brasil.

E-mail: tuanytel@hotmail.com

\section{Roberto Cassol}

Professor Doutor em Geografia Humana pela USP. Professor no Departamento de Geografia e Geociências e no Programa de Pós-graduação em Geografia da Universidade Federal de Santa Maria. Endereço postal: Departamento de Geografia e Geociências, Centro de Ciências Naturais e Exatas, Universidade Federal de Santa Maria. Caixa Postal 97105-900, Santa Maria, RS, Brasil.

E-mail: rtocassol@gmail.com

\section{Wilson de Oliveira Miranda}

Professor Doutor do Centro de Educação da Universidade Federal de Santa Maria (UFSM). Endereço: Depto. de Educação Especial/CE/ UFSM. Av. Roraima, ${ }^{\circ}$ 1000. Prédio 16. Cidade Universitária. CEP 97105900. Santa Maria/RS.

E-mail: wilsonmirandaufsm@gmail.com

Recebido para publicação em fevereiro de 2019 Aprovado para publicação em dezembro de 2019 